\title{
Effects of the combination of insulin and glibenclamide in Type 2 (non-insulin-dependent) diabetic patients with secondary failure to oral hypoglycaemic agents
}

\author{
S.Stenman, P.-H.Groop, C.Saloranta, K. J.Tötterman, F. Fyhrqvist and L. Groop \\ Fourth Department of Medicine, Helsinki University Central Hospital, Helsinki, Finland
}

\begin{abstract}
Summary. The effects of combined insulin and sulfonylurea therapy on glycaemic control and B-cell function was studied in 15 Type 2 (non-insulin-dependent) diabetic patients who had failed on treatment with oral hypoglycaemic agents. The patients were first treated with insulin alone for four months. Five patients were given two daily insulin doses and ten patients one dose. During insulin treatment the fasting plasma glucose fell from $14.5 \pm 0.8$ to $8.8 \pm 0.4 \mathrm{mmol} / 1$ and the $\mathrm{HbA}_{1}$ concentration from $12.6 \pm 0.4$ to $9.2 \pm 0.2 \%$. This improvement of glycaemic control was associated with a suppression of basal (from $0.31 \pm 0.04$ to $0.10 \pm 0.02 \mathrm{nmol} / \mathrm{l}$ ) and glucagon-stimulated (from $0.50 \pm 0.08$ to $0.19 \pm 0.04 \mathrm{nmol} / \mathrm{l}$ ) C-peptide concentrations. Four months after starting insulin therapy the patients were randomised to a four-month double-blind cross-over treatment with insulin combined with either $15 \mathrm{mg}$ glibenclamide per day or with placebo. Addition of glibenclamide to insulin resulted in a further reduction of the fasting plasma glucose $(7.9 \pm 0.5 \mathrm{mmol} / 1)$ and $\mathrm{HbA}_{1}(8.3 \pm 0.2 \%)$ concentration whereas the basal $(0.21 \pm$ $0.03 \mathrm{nmol} / \mathrm{l})$ and glucagon-stimulated C-peptide concentrations $(0.34 \pm 0.06 \mathrm{nmol} / \mathrm{l})$ increased again. Addition of placebo to insulin had no effect. The daily insulin dose could be reduced by $25 \%$ after addition of glibenclamide to insulin, while it remained unchanged when insulin was combined with placebo. The fasting free insulin concentration did not
\end{abstract}

differ between the glibenclamide and placebo periods $(28 \pm 6$ vs $30 \pm 5 \mathrm{mmol} / \mathrm{l})$. The fasting free insulin concentration correlated, however, positively with the insulin dose $(r=0.76$, $p<0.01)$ indicating that the insulin dose was the main determinant of the free insulin concentration. In contrast, the basal C-peptide concentration was higher during the insulin plus glibenclamide than during the insulin plus placebo period $(0.21 \pm 0.03$ vs $0.16 \pm 0.03 \mathrm{nmol} / 1 ; p<0.05)$. Addition of glibenclamide to insulin therapy increased the treatment cost by $30-50 \%$, was associated with increased frequency of mild hypoglycaemic reactions and with a slight, but significant fall in $\mathrm{HDL}$ cholesterol concentration (from 1.40 0.07 to $1.29 \pm 0.06 ; p<0.05$ ) compared with insulin plus placebo. We conclude that in Type 2 diabetic patients, who have failed on treatment with oral hypoglycaemic agents, the combination of insulin and glibenclamide resulted in slightly improved glycaemic control and allowed reduction of the insulin dose. The price for this improvement was higher treatment costs, more (mild) hypoglycaemic reactions and a marginal fall in the HDL cholesterol concentration. Whether the same effect could have been achieved with divided insulin doses in all patients is not known.

Key words: Type 2 (non-insulin-dependent) diabetes, insulin treatment, sulfonylurea, secondary failure, glibenclamide.
Secondary failure to treatment with oral hypoglycaemic agents is a common problem in the management of patients with Type 2 (non-insulin-dependent) diabetes mellitus, occurring with an annual rate of about $5-10 \%[1,2]$. Insulin therapy has been the treatment of choice in these patients, but excessive insulin doses resulting in weight gain are frequently required to control the hyperglycaemia [3]. In the search for alternative treatments, special interest has in the past years been focused on the combination of insulin and sulfonylureas [4-15]. Although most of these studies demonstrated a beneficial effect on glycaemic control during short term therapy $[6-11,13-15]$ two studies suggested that the effect may be attenuated with time
$[7,12]$. One could also argue that no attempts were made to optimise insulin therapy before starting combination therapy in the patients.

Controversies also remain as to the mechanism(s) by which the addition of sulfonylurea to insulin therapy improves the glucose control in a Type 2 diabetic patient. In the beginning of the sulfonylurea era, these compounds were added to insulin therapy in the hope that they would stimulate insulin secretion [16-17]. In addition to their effect on insulin secretion, sulfonylureas have been thought to improve glucose control by extrapancreatic mechanisms [18] resulting in potentiation of the effect of insulin. This concept provided the theoretical basis for the renewed interest in combina- 
tion therapy. However, studies which have examined the mechanisms of action of combination therapy have not provided support for such extrapancreatic effects $[7,9,19]$.

Type 2 diabetes is characterised by two major defects, enhanced hepatic glucose production in the basal state, resulting in an elevated fasting plasma glucose concentration, and impaired glucose disposal by peripheral tissues resulting in elevated postprandial plasma glucose concentrations [20-23]. Optimal control of glucose in a patient with Type 2 diabetes would require normalisation of both these defects. Previous studies did not quantify the relative effectiveness of combination therapy on fasting and postprandial glucose concentration.

To examine the effect of addition of glibenclamide to insulin therapy on glycaemic control and B-cell function, we randomised sixteen Type 2 diabetic patients, who had failed on treatment with oral hypoglycaemic agents, to a twelve-month double-blind crossover study, in which the effect of combination therapy was compared to the effect of insulin plus placebo. The cross-over design including placebo and two wash-out periods allowed us to exclude the possibility that changes in the measured variables would have been a time-related phenomenon.

\section{Subjects and methods}

\section{Subjects}

Sixteen Type 2 diabetic patients who had failed on treatment with maximum doses of oral hypoglycaemic agents were included in the study. None of the patients had secondary diabetes or clinical evi- dence of hepatic, renal or pulmonary dysfunction. One patient was treated for coronary heart disease and three patients for hypertension. One patient was excluded from the study after having a compression fracture of the femoral neck with subsequent thrombotic gangrene of the leg. The clinical data of the patients are shown in Table 1. The patients gave informed consent and the study protocol was approved by the Ethical Committee of the Fourth Department of Medicine, Helsinki University Central Hospital.

\section{Experimental protocol}

All patients were admitted to the hospital for confirmation of the diagnosis of secondary drug failure, which was defined as fasting plasma glucose repeatedly above $11 \mathrm{mmol} / \mathrm{l}$. Thereafter, treatment with oral hypoglycaemic agents was discontinued and insulin therapy instituted. Ten patients received one dose, five patients two doses of intermediary-acting insulin daily and two patients used a mixture of intermediary- and short-acting insulin in the the morning (Table 1). The patients remained in the hospital for two weeks, during which period they were given dietary instructions and were taught insulin injection technique and home monitoring of blood glucose. After discharge from hospital the patients were seen every two weeks in the Outpatient Metabolic Unit and the insulin dose was adjusted with the goal to achieve fasting plasma glucose $<8.0 \mathrm{mmol} / 1$ and $\mathrm{HbA}_{1}$ concentrations $<9 \%$. At the end of this ("basal") insulin treatment period, the patients were randomised to a double-blind treatment with insulin in combination with glibenclamide ("IG-period", $n=8$ ) or insulin and placebo ("IP-period", $n=8$ ) for four months. Identical-looking glibenclamide $(5 \mathrm{mg})$ or placebo tablets were given thrice daily. A one-month wash-out period (insulin and placebo) followed, after which the patients crossed over to the alternate treatment for another four months followed by a second one-month wash-out period. During the entire study period the patients visited the Outpatient Unit every 2-4 weeks, or more often if necessary. The patients obtained new, coded vials containing tablets every 4 weeks when they returned the previous vial.

The glibenclamide or placebo dose was kept constant throughout the study while the insulin dose was adjusted to achieve fasting blood glucose concentration $<8.0 \mathrm{mmol} / \mathrm{l}$ and $\mathrm{HbA}_{1}$ concentrations $<9 \%$. The insulin dose was, however, not divided during the crossover periods except for the 5 patients who had two daily doses of in-

Table 1. Clinical characteristics of patients at entry to the study and the insulin dose at the end of various test periods

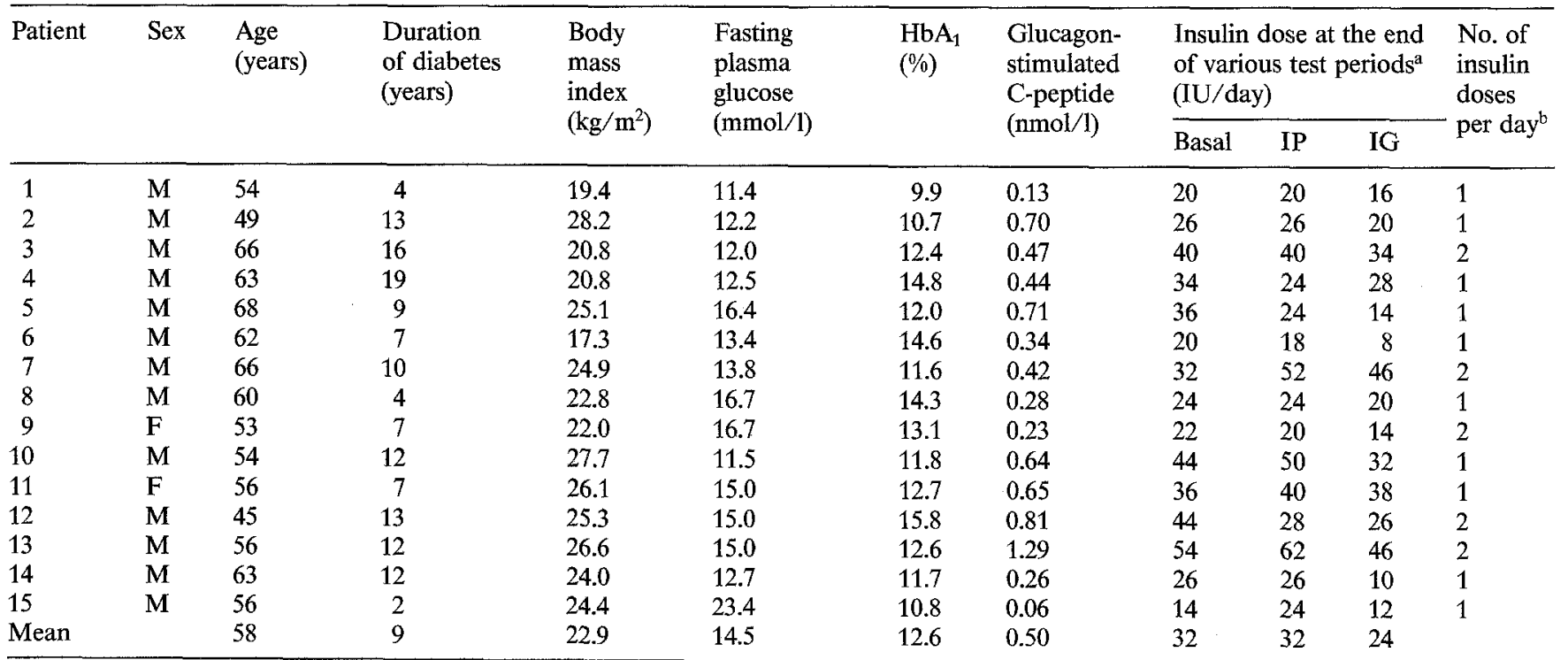

${ }^{a}$ Basal $=$ period of treatment with insulin alone; IP $=$ insulin and placebo; IG $=$ insulin and glibenclamide 5 mg three times daily; ${ }^{b}$ intermediateacting insulin was given either before breakfast ( 1 dose) or before breakfast and dinner ( 2 doses). Patients No 6 and 7 used a mixture of intermediate- and long-acting insulin 


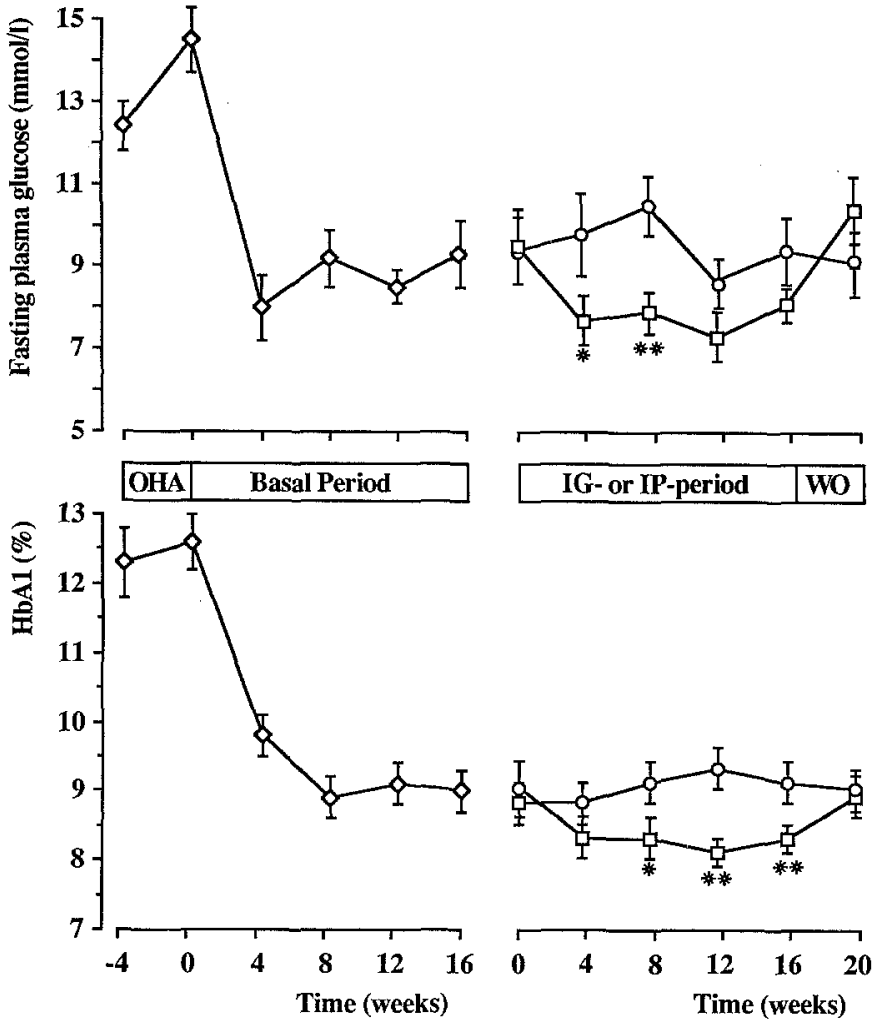

Fig. 1. Fasting plasma glucose (top panel) and $\mathrm{HbA}_{1}$ concentrations (bottom panel) in 15 Type 2 (non-insulin-dependent) diabetic patients who failed on treatment with oral hypoglycaemic agents (OHA), after starting insulin therapy (basal period) and after randomisation to either insulin plus glibenclamide (IG-period, $\square$ ) or insulin plus placebo (IP-period, 0 ). $\mathrm{WO}=$ wash-out period. The data represent mean ( \pm SEM) values from both IP- and IG-periods. ${ }^{*} p<0.05 ;{ }^{* *} p<0.01$ compared to the respective time points of the IP-period

sulin already during the basal period. The insulin dose was reduced by $2-4 \mathrm{IU} /$ visit if the patients reported hypoglycaemic episodes and/or if fasting plasma glucose concentrations were below $6 \mathrm{mmol} / \mathrm{l}$.

At each regular visit body weight was recorded and fasting concentrations of plasma glucose, glycohaemoglobin $\left(\mathrm{HbA}_{1}\right)$, total cholesterol, HDL cholesterol and triglycerides were measured. Urine was collected for $24 \mathrm{~h}$ for determination of glucose excretion.

B-cell function was assessed by measuring C-peptide concentrations before and $6 \mathrm{~min}$ after an intravenous injection of $1 \mathrm{mg}$ of glucagon (Novo Research Institute, Bagsvaerd, DK). This test was performed once during treatment with oral hypoglycaemic agents and during the basal and wash-out periods and twice during the IG- and IP-periods. B-cell function was further assessed by measuring Cpeptide response to a standard test meal once at the end of the basal period and twice during the IG- and IP-periods. Serum free insulin concentrations were measured in the fasting state and at 30,60 and $120 \mathrm{~min}$ after the test meals during the IG- and IP-periods. The test meal consisted of $20 \mathrm{~g}$ of whole wheat bread, $6 \mathrm{~g}$ margarine, $40 \mathrm{~g}$ cheese, $100 \mathrm{ml}$ low-fat milk, $120 \mathrm{ml}$ orange juice and a cup of coffee $(1600 \mathrm{~kJ})$. Blood was drawn for plasma glucose and serum C-peptide determinations at $-30,0,30,60,90,120$ and $180 \mathrm{~min}$ of the meal. All the tests were carried out at 08.00 hours after a 12 -h fast. The patients received their last medication (glibenclamide or placebo) before dinner of the evening before.

The patients monitored blood glucose at home every morning and once a week four times a day (before breakfast, before lunch, after dinner and at bed time) with a glucose oxidase strip (Visidex II, Ames Division, Miles Laboratories, Elkhart, Ind, USA).

\section{Assays}

Plasma glucose was measured by a hexokinase method (Boehringer Mannheim, Mannheim, FRG) and urine glucose by polarimetry. $\mathrm{HbA}_{1}$ concentration in blood was determined by cation exchange microcolumn chromatography (Isolab, Akron, Ohio, USA). The normal range for $\mathrm{HbA}_{1}$ concentration was 5.5-7.1\%. Serum cholesterol and triglyceride concentrations were measured enzymatically (Boehringer Mannheim) and serum HDL cholesterol after ultracentrifugation as previously described [24]. Serum C-peptide concentration was measured by radioimmunoassay [25] using antibody M1230 (Novo). The sensitivity of the assay was $0.02 \mathrm{nmol} / 1$. The coefficient of variation was $3 \%$ for a $\mathrm{C}$-peptide concentration of $0.13 \mathrm{nmol} / \mathrm{l}$ and $11 \%$ for a concentration of $1.4 \mathrm{nmol} / 1$. Serum free insulin concentrations were measured by radioimmunoassay after precipitation of insulin antibodies with acidification and addition of polyethylen glycol [26]. Interassay coefficient of variation was $9 \%$.

\section{Statistical analysis}

All data are expressed as means \pm SEM. The significance of difference between treatments was tested by multivariate analysis of variance for repeated measurements using a computer program. This program tested the effects of treatment, time and randomisation. Since there was no significant effect of randomisation, the data from identical treatment periods are presented together. After the first month there was no significant effect of time within a given treatment period. For the purpose of clarity both time-related data (Figs. 1 and 2) and pooled means (Tables 2-4) are presented from each treatment period. Differences in the frequency of hypoglycaemic reactions were tested by $\chi^{2}$ test. Correlations were tested by linear regression analysis.

\section{Results}

\section{The effect of insulin therapy}

The mean insulin dose at the end of the basal insulin treatment period was $32 \pm 3 \mathrm{IU} /$ day $(0.42 \pm 0.03 \mathrm{IU} \cdot \mathrm{kg}$ body weight ${ }^{-1}$. day ${ }^{-1}$; Table 1 ). With insulin therapy there was a significant increase in body weight from $70.3 \pm 2.8$ to $74.5 \pm 2.9 \mathrm{~kg}(p<0.01)$. Starting insulin therapy resulted in a marked reduction in fasting plasma glucose, $\mathrm{HbA}_{1}$ and $24 \mathrm{~h}$ urine glucose concentrations (all $p<0.001$; Table 2). Despite the improvement of metabolic control, insulin treatment resulted in a significant reduction in both basal (from $0.3 \pm 0.04$ to $0.10 \pm 0.02 \mathrm{nmol} / 1 ; p<0.001)$ and glucagon-stimulated serum C-peptide concentrations (from $0.50 \pm$ $0.08 \mathrm{nmol} / 1$ to $0.19 \pm 0.09 \mathrm{nmol} / 1 ; p<0.001$; Table 3). There was a significant reduction in serum triglyceride concentrations after starting insulin therapy $(p<0.05$; Table 4), whereas total cholesterol concentrations remained unchanged. HDL cholesterol was measured in only four patients before insulin therapy and in those patients insulin treatment was associated with a $30 \%$ increase of the HDL cholesterol concentration.

\section{Comparison between insulin plus glibenclamide (IG-period) and insulin plus placebo (IP-period)}

Insulin dose. The mean insulin dose (average from the entire period) was lower during the IG-period than 

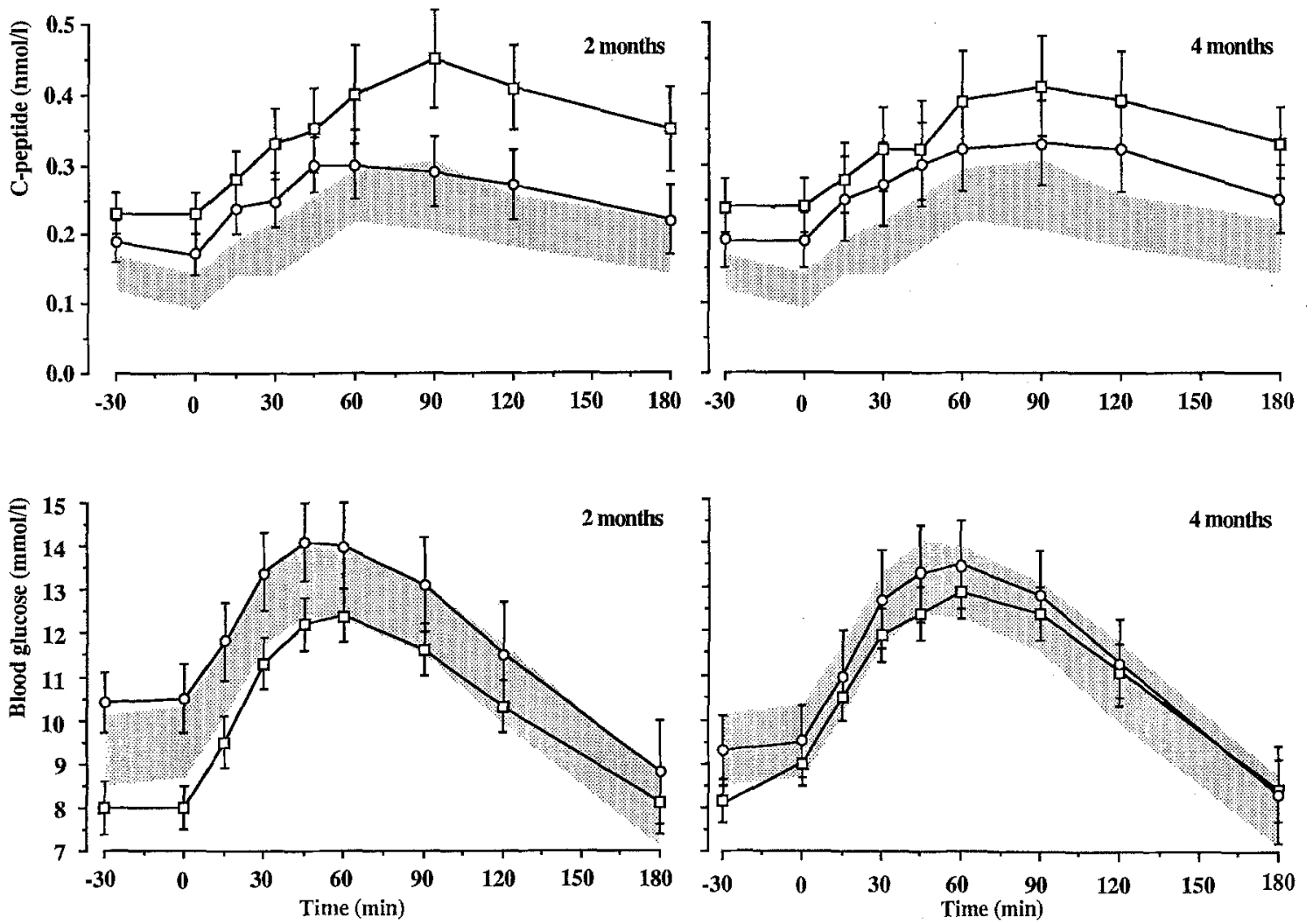

Fig. 2. Plasma glucose and C-peptide responses to a test meal after 2 and 4 months of treatment with insulin plus glibenclamide ( $\square$ ) or insulin plus placebo $(O)$ in 15 Type 2 diabetic patients who failed on treatment with oral hypoglycaemic agents. The plasma glucose and $C$-peptide responses during treatment with insulin alone (end of basal period) is shown as a shaded are. Values are means \pm SEM. The C-peptide concentrations are significantly higher during the IG period than during the basal period $(p<0.005)$, (see also Table 3 )

Table 2. Glycaemic control during treatment with oral hypoglycaemic agents (OHA), after starting insulin (basal period), and during treatment with insulin plus placebo (IP-period) or insulin plus glibenclamide $5 \mathrm{mg}$ thrice daily (IG-period) in 15 Type 2 diabetic patients who had failed on treatment with oral hypoglycaemic agents

\begin{tabular}{llllll}
\hline & \multicolumn{4}{l}{ Mode of treatment } \\
\cline { 2 - 6 } & OHA & Basal & IP-period & IG-period \\
\hline $\begin{array}{c}\text { Fasting plasma } \\
\text { glucose (mmol/l) }\end{array}$ & $14.5 \pm 0.8$ & $8.8 \pm 0.4^{\mathrm{a}}$ & $9.6 \pm 0.7$ & $7.9 \pm 0.5^{\mathrm{b}}$ \\
$\begin{array}{l}\mathrm{HbA}_{1}(\%) \\
\begin{array}{c}24 \mathrm{~h} \text { urinary } \\
\text { glucose }(\mathrm{g})\end{array}\end{array}$ & $12.6 \pm 0.4$ & $9.2 \pm 0.2^{\mathrm{a}}$ & $9.1 \pm 0.3$ & $8.3 \pm 0.2^{\mathrm{c}}$ \\
\hline
\end{tabular}

Results are expressed as mean \pm SEM. ${ }^{a} p<0.001$ vs the OHA period; ${ }^{b} p<0.05$ vs the basal period and $p<0.01$ vs the IP-period; ${ }^{c} p<$ 0.001 vs the basal and IP-periods; ${ }^{\mathrm{d}} p<0.05$ vs the basal and IP-periods

during the IP-period $(27 \pm 4 \mathrm{IU} /$ day vs $30 \pm 3 \mathrm{IU} /$ day; $p<0.05$ ). During the IG-period the insulin requirement decreased from $34 \pm 4 \mathrm{IU} /$ day at the beginning of the period to $24 \pm 3 \mathrm{IU} /$ day 4 months later $(p<0.001)$. In contrast, during the IP-period the insulin requirement increased from $26 \pm 3$ to $32 \pm 4 \mathrm{IU} /$ day $(p<0.01)$.

Body weight. There was an insignificant increase in body weight during both treatment periods: from $74.7 \pm 3.0$ to $76.6 \pm 3.3 \mathrm{~kg}$ during the IG-period and from $73.4 \pm 3.2$ to $75.5 \pm 2.9 \mathrm{~kg}$ during the IP-period. The mean body weights of the patients did not significantly differ between the two treatment periods.

Glycaemic control. The change in glycaemic control over time in relation to treatment is shown in Figure 1 and mean concentrations from each period in Table 2. The combination of insulin and glibenclamide resulted in significantly lower fasting plasma glucose $(p<0.05)$, $\mathrm{HbA}_{1}(p<0.001)$ and $24 \mathrm{~h}$ urine glucose concentrations $(p<0.05)$ than the combination of insulin and placebo. Likewise, home-monitored fasting $(7.4 \pm 0.5$ vs $9.1 \pm$ $0.6 \mathrm{mmol} / \mathrm{l} ; p<0.01)$ and mean blood glucose concentrations (mean of four measurements per day; 7.4 \pm 0.3 vs $8.1 \pm 0.5 \mathrm{mmol} / 1 ; p<0.02$ ) was lower during the IGthan during the IP-period. However, postprandial blood glucose values measured at home after dinner did not significantly differ between the IG- and the IPperiods $(8.0 \pm 0.6$ vs $8.8 \pm 0.7 \mathrm{mmol} / 1)$. Mild hypoglycaemic reactions were reported more often during the IG-period (by 13 patients; $6.1 \pm 1.0$ times per patient) than during the IP-period (by 8 patients, $2.6 \pm 1.0$ times per patient) $(p<0.01)$. No severe hypoglycaemic reactions requiring medical treatment occurred.

The plasma glucose response to the test meal tended to be lower during the IG- than during the IPperiod at 2 months ( $p=0.06$; Fig. 2$)$ but this difference 
Table 3. Serum C-peptide and free insulin concentrations during treatment with oral hypoglycaemic agents (OHA), after starting insulin (basal period), and during treatment with insulin plus placebo (IP-period) or insulin plus glibenclamide $5 \mathrm{mg}$ thrice daily (IG-period) in 15 Type 2 diabetic patients who had failed on treatment with oral hypoglycaemic agents

\begin{tabular}{|c|c|c|c|c|}
\hline & \multicolumn{4}{|c|}{ Mode of treatment } \\
\hline Fasting C-peptide & $0.31 \pm 0.04$ & $0.10 \pm 0.02^{\mathrm{d}}$ & $0.16 \pm 0.03^{\mathrm{e}}$ & $0.21 \pm 0.03^{\mathrm{f}}$ \\
\hline Post-meal C-peptide $(\mathrm{nmol} / \mathrm{l})^{\mathrm{b}}$ & & $0.19 \pm 0.01$ & $0.28 \pm 0.01^{\mathrm{e}}$ & $0.36 \pm 0.02^{\mathrm{g}}$ \\
\hline Fasting free insulin (mU/1) & & & $30 \pm 5$ & $28 \pm 6$ \\
\hline Post-meal free insulin $(\mathrm{mU} / 1)^{c}$ & & & $55 \pm 10$ & $46 \pm 9$ \\
\hline
\end{tabular}

Results are expressed as mean \pm SEM. ${ }^{a}$ Value obtained $6 \mathrm{~min}$ after injection of $1 \mathrm{mg}$ glucagon i.v.; ${ }^{\mathrm{b}}$ Mean value (averaged from blood samples drawn at $15,30,45,60,90,120$ and 180 min after the meal) from test meals at 2 and 4 months; ${ }^{\mathrm{c}}$ Mean value (averaged from blood samples drawn at 30,60 and $120 \mathrm{~min}$ after the meal) from test meals at 2 and 4 months; ${ }^{\mathrm{d}} p<0.001$ vs the OHA period; ${ }^{\mathrm{e}} p<0.05$ vs the basal period; ${ }^{\mathrm{f}} p<0.05$ vs the IP-period and $p<0.001$ vs the basal period; ${ }^{\mathrm{g}} p<0.005$ vs the basal period

Table 4. Serum lipid concentrations during treatment with oral hypoglycaemic agents (OHA), after starting insulin (basal period), and during treatment with insulin plus placebo (IP-period) or insulin plus glibenclamide $5 \mathrm{mg}$ thrice daily (IG-period) in 15 Type 2 diabetic patients who had failed on treatment with oral hypoglycaemic agents

\begin{tabular}{llccc}
\hline & \multicolumn{4}{l}{ Mode of treatment } \\
\cline { 2 - 5 } & OHA & Basal & IP-period & IG-period \\
\hline $\begin{array}{l}\text { Triglycerides } \\
\text { (mmol/l) }\end{array}$ & $1.50 \pm 0.17$ & $1.19 \pm 0.08^{\mathrm{a}}$ & $1.27 \pm 0.09$ & $1.31 \pm 0.09^{\mathrm{b}}$ \\
$\begin{array}{l}\text { Total cholesterol } \\
\text { (mmol/1) }\end{array}$ & $6.04 \pm 0.27$ & $6.06 \pm 0.36$ & $6.30 \pm 0.36$ & $6.04 \pm 0.33$ \\
$\begin{array}{l}\text { HDL-cholesterol } \\
(\mathrm{mmol} / \mathrm{l})\end{array}$ & & $1.35 \pm 0.07$ & $1.40 \pm 0.07$ & $1.29 \pm 0.06^{\mathrm{c}}$ \\
\hline
\end{tabular}

Results are expressed as mean \pm SEM. ${ }^{a} p<0.05$ vs the OHA period;

${ }^{\mathrm{b}} p<0.01$ vs the basal period; ${ }^{c} p<0.01$ vs IP-period

was mainly accounted for by the difference in fasting plasma glucose concentration $(p<0.01)$. There was no significant difference between the two periods regarding the plasma glucose response to the test meal at 4 months.

$B$-cell function. Independent of treatment added (glibenclamide or placebo) the basal and post-glucagon $\mathrm{C}$-peptide concentrations were higher during the crossover periods than during the basal insulin period $(p<$ 0.01-0.05), suggesting time-related recovery of B-cell function (Table 3). The basal C-peptide concentration was significantly higher during the IG- than during the IP-period $(p<0.05)$.

The mean C-peptide response to the test meal increased significantly from $0.19 \pm 0.01 \mathrm{nmol} / \mathrm{l}$ at the end of the basal period to $0.36 \pm 0.02 \mathrm{nmol} / 1$ during the IG-period $(p<0.005)$. This value was, however, not significantly higher than that obtained during the IP-period $(0.28 \pm 0.01 \mathrm{nmol} / 1)$. The fasting and postprandial free insulin concentrations did not significantly differ between the IG- and IP-periods. There was a strong positive correlation between daily insulin dose and fasting free insulin concentration $(r=0.76 ; p<0.001)$ and between the morning insulin dose and the free insulin concentrations measured after the test meal at
08.00 hours $(r=0.77 ; p<0.001)$. These relationships indicate that the insulin dose was the major determinant of the serum free insulin concentration in these patients.

The reduction in $\mathrm{HbA}_{1}$ concentration during the IG-period (difference between the IG- and IP-periods) correlated inversely with the increase in basal C-peptide concentration during the IG-period (difference between the IG- and IP-periods; $r=-0.50 ; p<0.05$ ). There was also a modest inverse correlation between the suppression of post-glucagon C-peptide after starting insulin (difference between the treatment with oral hypoglycaemic agents and the basal insulin treatment period) and the stimulation of post-glucagon C-peptide after adding glibenclamide to insulin treatment (difference between the IG- and the basal period; $r=-0.54 ; p<0.05$ ). This suggests that glibenclamide could, at least partly, overcome the suppression of endogenous insulin secretion caused by exogenous insulin.

Serum lipids. Serum triglyceride concentrations during the IG- and IP-periods did not differ significantly from each other (Table 4) but they were higher during the IG-period than during the basal period $(p<0.01)$. Total serum cholesterol concentations were not influenced by changing the treatment. However, the HDL cholesterol concentration was lower during the IG- than during the IP-period $(p<0.05)$.

Serum triglyceride concentrations correlated positively with basal $\mathrm{C}$-peptide concentrations during both the IG- $(r=0.63 ; p<0.01)$ and the IP-periods $(p<$ 0.001 ) whereas HDL cholesterol concentrations correlated inversely (IG-period $r=-0.72 ; p<0.01$; IP-period $r=-0.56 ; p<0.05)$ with the basal C-peptide concentrations (Fig. 3).

\section{Discussion}

In our patients previously treated with oral hypoglycaemic agents, starting insulin therapy alone resulted in a marked improvement of glycaemic control. When 
glibenclamide later was added to insulin, glycaemic control further improved. When, on the other hand, placebo instead of glibenclamide was added to insulin, glycaemic control was similar to that obtained with insulin alone. The improvement of glycaemic control after addition of glibenclamide allowed a reduction of the insulin dose by $25 \%$. In contrast, after addition of placebo to insulin, the insulin requirement was the same as during treatment with only insulin. According to the protocol the insulin dose was increased if the fasting plasma glucose concentration was over $8 \mathrm{mmol} / \mathrm{l}$. Despite a significant increase in the insulin dose during the insulin plus placebo period, we were not able to achieve the treatment goal in all patients. Simply increasing the morning insulin dose was, therefore, not sufficient to control fasting hyperglycaemia in all patients. It is, though, quite possible that by using two or more insulin injections in all patients, the fasting plasma glucose concentration could have been lowered to the same level as seen after addition of glibenclamide. This was, however, not included in the design of this study. However, if one compares treatment with one versus two daily insulin doses, the results in these two groups were identical (e.g. $\mathrm{HbA}_{1}$ values for 1 dose and 2 doses, respectively, were during the IPperiod 9.1 and $9.2 \%$ and during the IG-period 8.3 and $8.2 \%$ respectively).

In the present study the fasting plasma glucose concentration improved more than the postprandial glucose concentration, and this was further associated with a marked reduction in the $\mathrm{HbA}_{1}$ concentration. Our data thus agree with two recent reports $[9,15]$ which showed lower fasting blood glucose and $\mathrm{HbA}_{1}$ concentrations after four months of combined insulin and glibenclamide treatment in poorly controlled Type 2 diabetic patients. In keeping with our findings they did not observe any significant effect of the combination therapy on the oral glucose tolerance. Combination therapy, therefore, seems to influence fasting more than postprandial plasma glucose concentrations.

There is a strong positive correlation between fasting plasma glucose concentration and basal hepatic glucose production in diabetic patients [20-23, 27, 28]. Attempts to lower fasting plasma glucose should, therefore, include means to suppress hepatic glucose output. Sulfonylureas have been shown to suppress hepatic glucose production either directly or by stimulation of insulin secretion [27-29]. Although hepatic glucose production was not quantified in this study, greater suppression of hepatic glucose production during the IG- than during the IP-period most likely explains the difference in fasting plasma glucose concentrations between the two treatment periods. The liver is very sensitive to small increments in portal insulin; and hepatic glucose production is supressed by $50 \%$ when portal insulin levels are raised with only $10 \mathrm{mU} / 1$ [30-32]. The basal free insulin concentration was, how- ever, virtually similar during the two periods. It should be noted that the insulin dose was reduced by $25 \%$ during the IG-period compared with the IP-period. As shown by the strong positive correlation between the insulin dose and the serum free insulin concentration, the insulin dose is the major determinant of the free insulin concentration. Furthermore, subcutaneously injected insulin passes through the circulation before it reaches the liver, and the serum free insulin concentration is, consequently, a poor measure of portally-secreted insulin. Basal C-peptide concentrations, on the other hand, represent a fairly reliable measure of endogenous insulin secretion [33]. Addition of glibenclamide to insulin caused a slight, but significant increase in the fasting C-peptide concentration. These data indicate that more insulin was secreted in the postabsorptive state during the IG- than during the IP-period. In fact, the reduction in $\mathrm{HbA}_{1}$ during the IG-period was inversely correlated with the increase in fasting $\mathrm{C}$-peptide concentration indicating that stimulation of basal insulin secretion contributed to the improvement in glycaemic control.

Starting of insulin therapy resulted in a marked reduction of basal C-peptide concentration. Part of this decrease can be accounted for by lower ambient plasma glucose concentrations [34]. Inhibition of insulin secretion by exogenous insulin serves as another explanation $[35,36]$. The fact that the plasma glucose concentration was similar,whereas the C-peptide concentration was greater during the IP- than during the basal insulin period could suggest that inhibition of insulin secretion by exogenous insulin is more important than the effect of the prevailing glucose concentration. Partial recovery of insulin secretion with time could serve as another explanation. The addition of an insulinotropic sulfonylurea seemed to accelerate this recovery. In fact, the increase in the basal C-peptide concentration during the IG-period correlated inversely with reduction of the C-peptide concentration after starting insulin therapy. This suggests that the greater the inhibition by exogenous insulin, the greater was the stimulation of insulin secretion by glibenclamide [37].

Postprandial plasma glucose response, on the other hand, is mainly determined by the total body glucose uptake, which reflects glucose uptake by muscles [38]. We could not demonstrate any significant improvement in postprandial glucose tolerance after adding glibenclamide to insulin. However, one should keep in mind that the Michaelis' constant (approximately $120 \mathrm{mU} / \mathrm{l}$ ) for stimulation of peripheral glucose uptake by insulin is much higher than that for inhibition of hepatic glucose output [39]. The serum free insulin concentrations achieved after the test meal ( 46 to $55 \mathrm{mU} / \mathrm{l}$ ) were clearly below this level. As a consequence of the reduced insulin dose, the post-meal free insulin concentrations tended to be lower during the IG- than during the IP-period. Premeal administration of short acting insulin would most likely be necessary to 


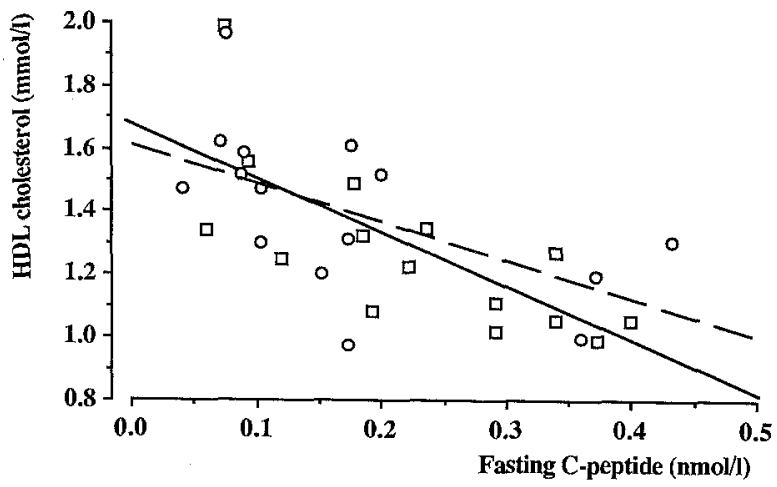

Fig. 3. Linear correlation between fasting C-peptide and HDL cholesterol concentration during treatment with insulin plus glibenclamide $(-\square ; r=-0.72 ; p<0.01)$ or insulin plus placebo $(--O$; $r=-0.56 ; p<0.05)$ in 15 patients who had failed on treatment with oral hypoglycaemic agents. Data from samples taken after 4, 8, 12 and 16 weeks of treatment are pooled

achieve serum free insulin concentrations which could promote postprandial peripheral glucose uptake and thereby, control of postprandial hyperglycaemia. In keeping with the present results, we already in an earlier study have shown a significant increase in the Cpeptide response to meals, which was, however, not associated with improved meal glucose tolerance [7]. Although we did not measure glucose uptake or insulin sensitivity in this study, two previous studies failed to demonstrate any effect of combination therapy on insulin sensitivity or peripheral glucose uptake [7, 9]. It is, therefore, unlikely that extrapancreatic mechanisms would play a major role in the improvement of glycaemic control observed during combination therapy.

The better glycaemic control observed during the IG- as compared to the IP-period was, however, associated with a small reduction of plasma HDL cholesterol concentration. Furthermore, the HDL cholesterol concentration was inversely correlated to the C-peptide concentration, i.e. the higher the $\mathrm{C}$-peptide, the lower the HDL cholesterol concentration (Fig. 3). The reduction of HDL cholesterol concentration during the IG-period could, therefore, be a consequence of, or related to, the increase in basal C-peptide concentration. The question remains whether this small decrease in HDL cholesterol concentration has an influence on cardiovascular morbidity and mortality.

Another side effect of combination treatment observed in this study was more frequent hypoglycaemic reactions. The hypoglycaemic episodes were reported mainly during the first four to eight weeks of the IGperiod and they disappeared after reduction of the insulin doses. No sustained or severe hypoglycaemic reactions requiring treatment were observed.

Finally, the cost of combination therapy compared to treatment with a higher dose of insulin deserves some comment. Addition of three tablets of glibenclamide will increase treatment costs by about $70 \%$. A reduction of the insulin dose by $25 \%$ would decrease the additional costs to about $50 \%$. If multiple injections were to be used to achieve the same goal, the difference would be even less, about 30\%. Against this, one has to consider the economical benefits of better disease control.

In conclusion, during the clinical conditions used in this study we observed that patients with Type 2 diabetes had better glycaemic control with a smaller total insulin dose when glibenclamide instead of placebo was added to insulin. Since the design of the study did not include change in the mode of insulin treatment after the basal period, it is not known whether the same effect could have been obtained by dividing the insulin dose in all patients. The improvement in glycaemic control was primarily seen in the fasting state and was most likely a consequence of better suppression of hepatic glucose production by enhanced basal insulin secretion. This improvement in glucose control was, however, associated with a modest reduction in HDL cholesterol concentrations and an increased frequency of mild hypoglycaemic reactions.

Acknowledgements. We thank the patients who participated in the study and Ms S. Heikkinen for her skilful technical assistance. Financial support was obtained from the Sigrid Jusélius Foundation, The Finnish Medical Association (Finska Läkaresällskapet) and the Signe and Ane Gyllenberg Foundation. Glibenclamide (Daonil) and placebo tablets were kindly provided by Hoechst AG, Frankfurt, FRG.

\section{References}

1. Shen S-W, Bressler R (1977) Clinical pharmacology of oral antidiabetic agents. N Engl J Med 296: 787-793

2. Haupt E, Laube F, Loy H, Schöffling K (1977) Secondary failures in modern therapy of diabetes mellitus with blood glucose lowering sulfonamides. Med Klin 72: 1529-1536

3. Peacock I, Tattersall RB (1984) The difficult choice of treatment for poorly controlled maturity onset diabetes: tablets or insulin? Br Med J 288: 1956-1959

4. Rizza RA (1985) Combined sulfonylurea and insulin therapy in insulin-dependent diabetes: research or practice? Diabetes Care 8: $511-514$

5. Riddle MC (1985) New tactics for Type 2 diabetes: regimen based on intermediate-acting insulin taken at bedtime. Lancet I: 192-195

6. Groop L, Harno K, Tolppanen E-M (1984) The combination of insulin and sulfonylurea in the treatment of secondary drug failure in patients with type II diabetes. Acta Endocrinol 106: $97-101$

7. Groop L, Harno K, Nikkilä EA, Pelkonen R, Tolppanen E-M (1985) Transient effect of the combination of insulin and sulfonylurea (glibenclamide) on glycemic control in non-insulin dependent diabetics poorly controlled with insulin alone. Acta Med Scand 217: 33-39

8. Kyllästinen M, Groop L (1985) Combination of insulin and glibenclamide in the treatment of elderly non-insulin dependent (type 2) diabetic patients. Ann Clin Res 17: 100-104

9. Simonson DC, Del Prato S, Castellino P, Groop L, DeFronzo RA (1987) Effect of glyburine on glycemic control, insulin requirement, and glucose metabolism in insulin-treated diabetic patients. Diabetes 36: 136-146

10. Hamelbeck H, Klein W, Zoltobrocki M, Schöffking K (1982) Glibenclamid-Insulin-Kombinationsbehandlung beim Sekundär- 
versagen der Sulphonylharnstoff-Therapie. Dtsch Med Wochenschr 107: 1581-1583

11. Burke BJ, Hartog M, Waterfield MR (1984) Improved diabetic control in insulin-dependent diabetics treated with insulin and glibenclamide. Acta Endocrinol 107: 70-77

12. Osei K, O'Dorisio T, Falko JM (1984) Concomitant insulin and sulfonylurea therapy in patients with type II diabetes. Am J Med 77: 1002-1009

13. Longnecker MP, Elsenhans VD, Leiman SM, Owen OE, Boden G (1986) Insulin and sulfonylurea agent in non-insulin dependent diabetes mellitus. Arch Intern Med 146: 673-676

14. Traumann KJ, Hösl W, Grom E, Wittemann G (1982) Kombination von Insulin und Sulphonylharnstoffen bei der Therapie des Diabetes mellitus vom Erwachsenen-Typ. Dtsch Med Wochenschr 107: 180-184

15. Schade DS, Mitchell WJ, Griego G (1987) Addition of sulfonylurea to insulin treatment in poorly controlled Type II diabetes. A double-blind, randomized clinical trial. JAMA 257: 2441-2445

16. Fabrykant M (1957) Favourable effects of supplemental orinase in insulin-treated labile diabetes. Metabolism 6: 509-517

17. Friedlander EO (1957) Use of tolbutamide in insulin resistant diabetes. N Engl J Med 257: 11-14

18. Feldman JM, Lebovitz HE (1969) Appraisal of the extrapancreatic actions of sulfonylureas. Arch Intern Med 123:314-322

19. Burke BJ, Sheriff RJ (1980) Stimulation of residual insulin secretion by glibenclamide in insulin dependent diabetics. Acta Endocrinol 95: 372-375

20. Nankervis A, Proietto J, Aitken P, Harewood M, Alford F (1982) Differential effects of insulin therapy on hepatic and peripheral insulin sensitivity in type 2 (non-insulin-dependent) diabetes. Diabetologia 23: 320-325

21. DeFronzo RA, Simonson D, Ferrannini E (1982) Hepatic and peripheral insulin resistance: a common feature of type 2 (noninsulin-dependent) diabetes mellitus. Diabetologia 23: 313-319

22. Bogardus C, Lillioja S, Howard B, Reaven G, Mott D (1984) Relationships between insulin secretion and fasting plasma glucose concentration in non-diabetic and non-insulin dependent diabetic subjects. J Clin Invest 74: 1238-1246

23. Kolterman O, Gray R, Griffin J, Burstein P, Scarlett J, Olefsky J (1981) Receptor and postreceptor defects contribute to the insulin resistance in non-insulin-dependent diabetes mellitus. J Clin Invest 68: 657-669

24. Finley PR, Schifman RB, Williams RJ, Lahti DA (1978) Cholesterol in high density lipoprotein: use of $\mathrm{Mg}^{++}$dextrane sulphate in its enzymatic measurement. Clin Chem 24: 931-933

25. Heding LG (1975) Radioimmunological determination of human C-peptide in serum. Diabetologia 11: 541-548

26. Kuzuya H, Blix DM, Horwitz DL, Steiner DF, Rubenstein, AH (1977) Determination of free and total insulin and C-peptide in insulin-treated diabetics. Diabetes 26: 22-29

27. Best J, Judzewisch R, Pfeifer M, Beard J, Halter J, Porte D (1982) The effect of chronic sulfonylurea therapy on hepatic glucose production in non-insulin dependent diabetes. Diabetes 31: $333-338$
28. Groop L, Luzi L, Melander A, Groop P-H, Ratheiser K, Simonson DC, DeFronzo R (1987) Different effects of glibenclamide and glipizide on insulin secretion and hepatic glucose production in normal and NIDD subjects. Diabetes 36: 1320-1328

29. Blumenthal SA (1977) Potentiation of hepatic action of insulin by chlorpropamide. Diabetes 26: 485-489

30. Fukagawa NK, Minaker KL, Young VR, Rowe JW (1986) Insulin dose dependent reductions in plasma amino acids in man. Am J Physiol 250: E13-E17

31. Nurjhan N, Cambell PJ, Kennedy FP, Miles JM, Gerich JE (1986) Insulin dose-response characteristics for suppression of glycerol release and conversion to glucose in humans. Diabetes 35: 1326-1331

32. Groop L, Bonadonna R, Ratheiser K, Zych K (1986) Suppression of FFA turnover and FFA oxidation is impaired in NIDDM. Diabetes 35 [Suppl. 1]: 155

33. Polonsky KS, Pugh W, Jaspan JB, Cohen DM, Karrison T, Tager HS, Rubenstein AH (1984) C-peptide and insulin secretion. Relationship between peripheral concentrations of C-peptide and insulin and their secretion rates in the dog. J Clin Invest 74: 1821-1829

34. Brunzell JD, Robertson RP, Lerner RL, Hazzard WR, Ensinck JW, Bierman EL, Porte Jr D (1976) Relationships between fasting plasma glucose levels and insulin secretion during intravenous glucose tolerance tests. I Clin Endocrinol Metab 42: $222-229$

35. DeFronzo RA, Binder C, Wahren J, Felig P, Ferrannini E, Faber OK (1981) Sensitivity of insulin secretion to feedback inhibition by hyperinsulinaemia. Acta Endocrinol 98: 81-86

36. Elahi D, Nagulesparan M, Hershcopf RJ, Muller DC, Tobin JD, Blix PM, Rubenstein AH, Unger RH, Andrés R (1982) Feedback inhibition of insulin secretion by insulin: relation to hyperinsulinemia of obesity. N Engl J Med 306: 1196-1202

37. Lazarus SS, Volk BW (1959) Physiological basis of the effectiveness of combined insulin - tolbutamide therapy in stable diabetes. Ann N Y Acad Sci 82: 590-602

38. Katz LD, Glickman MG, Rapoport S, Ferrannini E, DeFronzo RA (1983) Splanchnic and peripheral disposal of oral glucose in man. Diabetes 32:675-679

39. DeFronzo RA, Ferrannini E, Hendler R, Felig P, Wahren J (1983) Regulation of splanchnic and peripheral glucose uptake by insulin and hyperglycaemia in man. Diabetes $32: 35-45$

Received: 23 March 1987

and in revised form: 16 February 1988

Dr. L.Groop

Fourth Department of Medicine

Helsinki University Central Hospital

Unioninkatu 38

SF-00190 Helsinki

Finland 